\title{
Prenatal, perinatal, and postnatal factors associated with autism spectrum disorder cases in Xuzhou, China
}

\author{
Zenghua Yong ${ }^{1 \#}$, Yunlong Dou ${ }^{1 \#}$, Yuchen Gao ${ }^{1}$, Xuena $\mathrm{Xu}^{1}$, Yanli Xiao ${ }^{1}$, Hongjuan $\mathrm{Zhu}^{1}$, Shengli $\mathrm{Li}^{2}$, \\ Baoqiang Yuan ${ }^{1}$ \\ ${ }^{1}$ Children's Neurological Rehabilitation Center, The Affiliated Hospital of Xuzhou Medical University, Xuzhou, China; ${ }^{2}$ Department of Medical \\ Records, The Affiliated Hospital of Xuzhou Medical University, Xuzhou, China \\ Contributions: (I) Conception and design: Z Yong, Y Dou, B Yuan; (II) Administrative support: B Yuan; (III) Provision of study materials or patients: \\ All authors; (IV) Collection and assembly of data: X Xu, Y Xiao; (V) Data analysis and interpretation: Y Xiao, H Zhu, S Li; (VI) Manuscript writing: \\ All authors; (VII) Final approval of manuscript: All authors. \\ \#These authors contributed equally to this work. \\ Correspondence to: Baoqiang Yuan. Children's Neurological Rehabilitation Center, The Affiliated Hospital of Xuzhou Medical University, No. 99 \\ Huaihai West Road, Xuzhou 221002, China. Email: yuanbqiang@hotmail.com.
}

Background: The aim of the present study was to explore the prenatal, perinatal, and postnatal risk factors in children with autism spectrum disorder (ASD) from Xuzhou, China by comparing them with healthy children.

Methods: Children with ASD who received rehabilitation training at special education schools and rehabilitation institutions in Xuzhou were selected as the ASD group, and healthy children during the same period were selected as the healthy non-ASD group. A questionnaire based on the possible causes and susceptibility factors of ASD in children was issued and given to all children in this study.

Results: The findings of the present study revealed a higher prevalence of prenatal, perinatal, and postnatal factors in children with ASD compared with healthy children. There were significantly more males than females in the ASD group, and the proportion of boys to girls was 5.81:1 $(\mathrm{P}<0.05)$. Logistic regression analysis suggested that the risk factors of male children developing ASD were feeding difficulties, poor living environment during pregnancy, maternal exposure to cigarette smoking during pregnancy, and perinatal hypoxia. Factors associated with ASD risk among were identified, such as living environment during pregnancy, delivery method, feeding difficulties, and epilepsy $(\mathrm{P}<0.05)$. Feeding difficulties and living in the countryside during pregnancy might be risk factors for ASD in girls according to the logistic regression analysis.

Conclusions: This survey confirmed the high prevalence of prenatal, perinatal, and postnatal factors in children with ASD. Some of these factors may be effective entry points for the prevention and treatment of ASD.

Keywords: Autism spectrum disorders (ASDs); prenatal; perinatal; postnatal; occupational therapy

Submitted Dec 24, 2020. Accepted for publication Mar 16, 2021.

doi: $10.21037 / \mathrm{tp}-21-54$

View this article at: http://dx.doi.org/10.21037/tp-21-54

\section{Introduction}

Autism spectrum disorders (ASDs) are a group of complex neurodevelopmental disorders that are lifelong; their pathogenesis remains unclear. The latest statistics from the Centers for Disease Control and Prevention (CDC) on the prevalence of ASD in the United States is 1/59, an increase of $15 \%$ compared with the data released in 2014. The specific diagnostic criteria for childhood autism include social skills and communication deficit associated with restrictive and repetitive behaviors, interests, or activities 
based on the 5th edition of the Diagnostic Statistical Manual of Mental Disorders (DSM-5) (1). The prevalence of ASD has risen significantly in the past 20 years from 4.8 per 10,000 in 1979 to 116.1 per 10,000 in 2006 in the UK (2), and from 113 per 10,000 in 2012 to 1 per 59 children in 2018 in the USA (1). Rehabilitation costs for ASD patients were higher than those for neurotypical children in the USA in 2014 (3). The increasing in the population and the rising cost of rehabilitation for those with ASD have become a serious social problem. The pathogenesis and mechanism of ASD are unknown. It was initially believed that the etiology of ASD was heterologous, including environment, infection, immunity, perinatal period, epilepsy and comorbidities, neuroanatomy and imaging, genetics, and social psychology. These factors are likely to have an important impact on the pathogenesis of ASD. However, it is believed that the mechanism underlying ASD etiology is most likely to be polygenic and potentially epistatic, and those environmental factors may interact with genetic factors to increase risk (4).

Most researchers consider genetic factors to play an important role in the etiology of ASD $(4,5)$. Studies on twins have identified high heritability, showing that the prevalence of identical twins in a child with ASD was $88 \%$. Also most siblings of a child with ASD are at higher risk of autism and other developmental disorders. Over 3000 genes and thousands of gene variants have been identified to date, including rare mutations and common polymorphisms, which might be associated with ASD. Increasing evidence shows that ASD heritability has complex heterogeneity, and the genetic variability responsible for ASD can be successfully identified in approximately $20-30 \%$ of cases (6). Other while, boys are at a higher risk of autism according to CDC, reporting that ASD is about 4.5 times more common among boys, which is considered to be due to a gene abnormality in the sex chromosome (7). However, more and more literature show that genetic factors possibly account for only $35-40 \%$ of the causes of autism. The remaining $60-65 \%$ are likely due to other factors such as environmental pollution. Recently published studies investigated that the interaction between gene and environment can lead to autism (8).

The fact that the occurrence of autism in monozygotic twins is not completely consistent suggests that environment is also an important cause of autism, including prenatal, perinatal and environmental factors $(1,9)$. The first report about complications during pregnancy and their association with the risk of autism was published in 1956 (10). Three papers, including a large meta-analysis, were published before 2007 and some recently published articles have focused on the significance of individual factors in the development of ASD $(5,11)$. More and more studies have found that several perinatal and postpartum factors could be the cause of ASD $(11,12)$, such as umbilical cord complications, fetal distress, birth injury or trauma, multiple births, maternal hemorrhage, premature delivery, low or very low birth weight, size small for gestational age, congenital malformations, low 5-min Apgar score, feeding difficulties, neonatal anemia, and hyper-bilirubinemia. These studies also showed that ASD factors of prenatal, perinatal, and environmental varied among regions.

There are few studies in China that consider the relationship between prenatal, perinatal, and postnatal risk factors with ASD $(13,14)$. Therefore, the aim of the present study was to identify the prenatal, perinatal, postnatal, and environmental factors associated with ASD by comparing children with ASD with neurotypical children.

We present the following article in accordance with the STROBE reporting checklist (available at http://dx.doi. org/10.21037/tp-21-54).

\section{Methods}

\section{Participants}

The participants were divided into 2 groups: the ASD group and the healthy group. This study was approved by ethics committee of the Affiliated Hospital of Xuzhou Medical University (NO. XYFY2020-KL151-01). Written informed consent was obtained from parents of guardians of study participants $<16$ years of age. All procedures performed in this study involving human participants were in accordance with the Declaration of Helsinki (as revised in 2013).

\section{ASD group}

All cases with ASD were selected from special educational schools and autism rehabilitation facilities in Xuzhou, north of Jiangsu Province, located in the middle eastern part of China, from March 2016 to March 2018. These schools and facilities are affiliated with China Disabled Persons' Federation (CDPF) in Xuzhou, and their employees have received CDPF's technical guidance on autism rehabilitation.

Children with ASD in the present study met following criteria: (I) DSM-5 criteria for ASD; (II) Child Autistic Rating Scale score $\geq 30$; (III) Autism Birth Cohort (ABC) score $\geq 67$ (15); and (IV) The informed consent of the guardian was obtained The exclusion criteria were 
known neurogenetic conditions (e.g., tuberous sclerosis, neurofibromatosis, fragile X syndrome, Down syndrome, phenylketonuria), congenital malformations, brain injuries, encephalitis, or other encephalopathies, or visual and hearing impairments.

\section{Healthy group}

Children in the healthy group had normal intelligence, normal development, and no physical and mental illnesses, as confirmed by the class teacher or school doctor. These children matched the ASD cases by age and sex and were selected from the same administrative district kindergarten and primary school from June 2017 to March 2018. The parents of children in the healthy groups agreed to complete the survey.

\section{Questionnaire and procedures}

The research team designed a questionnaire on the etiology and susceptibility of children with ASD according to previously published studies (15). The questionnaire comprised 10 items and 155 subitems covering the basic information of the children, including illnesses, family genetic factors, health status of the parents during the mother's pregnancy, childbearing history feeding and growth history before 2 years of age, past medical history of child, vaccinations, parental occupation and education, and drug and food allergies.

From a procedural point of view, research group staff first explained the purpose and significance of the study to the parents or guardians and teachers who knew the child for at least 6 months and understood the disease status of the children under investigation. The parents and teachers were then provided consent. The research staff explained in detail the questionnaire to the parents and answered their questions to minimize confusion and misunderstanding. The quality of the questionnaire data was then evaluated. Returned questionnaires with more than $10 \%$ of unanswered questions or unclear responses were considered invalid. The researchers completed the questionnaires with missing or unclear responses by follow-up with parents via telephone, email, WeChat, and Tencent QQ (an instant messenger issued by Tencent Company).

\section{Statistical analysis}

After checking the original data, the cases that did not meet the inclusion criteria were excluded. The data of the ASD group and the healthy group were recorded using EpiData software (http://www.epidata.dk/).

According to the questions setting in the questionnaire, it was divided into 2 kinds of variables: two classification variables and grade variables. For 2 classification variables, the value " 0 " indicated "none or nonexistence", and the value "1" indicated "expressed or existed". The maternal age during pregnancy, maternal duration of illness during pregnancy, parents' smoking and drinking history, general situation of infant birth, postpartum feeding methods, main rearing methods, children's past disease and treatment history, parents' occupation and education level were divided into $0,1,2,3$ grades, and 4 grades.

Statistical data were analyzed using SPSS version 19.0 (IBM, Armonk, NY, USA). In the present study, the measurement data were represented by mean \pm standard deviation $(\bar{x} \pm s)$, and compared with $t$-test. Enumeration data were expressed as number of cases or percentages and analyzed by $\chi^{2}$-test. The categorical data in the ASD group and healthy group were tested by $\chi^{2}$-test. If the test results show that there is a significant gender difference between the two groups, that is, there is an imbalance in the proportion of internal structure between the two groups, then stratified 2 tests based on gender classification is conducted. All variables with difference by $t$ or $\chi^{2}$-test were considered in the regression equation and logistic regression analysis was carried out. $\mathrm{P}<0.05$ indicated statistically significant differences.

A bivariate logistic regression was also conducted to generate crude odds ratios (ORs) with $95 \%$ confidence intervals (CIs). A multivariable logistic regression was conducted for significant variables $(\mathrm{P}<0.05)$ and borderline significant variables, and adjusted ORs with $95 \%$ CIs were generated. A stepwise logistic regression was then used to generate a final model. Adjusted ORs and their 95\% CIs were reported.

\section{Results}

\section{Gender and demographic characteristics of ASD children}

In the healthy group, 201 cases [119 males (59.2\%) and 82 females $(40.8 \%)$ ] met the control group's admission criteria. The male-to-female ratio in this group was $1.4: 1$. In the ASD group, 190 questionnaires were issued, of which 177 cases [151 males (85.3\%) and 26 females (14.7\%)] met the ASD criteria. The male-to-female ratio in the ASD group 
Table 1 Comparison of general information of children in the healthy group and autism spectrum disorder (ASD) group

\begin{tabular}{lcc}
\hline Projects & Healthy group (n) & ASD group (n) \\
\hline No. questionnaires & 210 & 202 \\
Reclaimed number of questionnaires & 201 & 190 \\
Complied with the standard set of questionnaires & 119 & 177 \\
Males & 82 & 151 \\
Females & $1.4: 1$ & 26 \\
Male-to-female ratio & 1 & 12.1 \\
No. twins & 1 & 12 \\
No. cases with epilepsy & 14 & 21 \\
No. cases with febrile convulsion & 0 & 4 \\
No. cases with febrile convulsion and epilepsy & 0 & 3 \\
No. cases with a family history of mental illness & 1 & 1 \\
No. cases with a family history of ASD history & 0 & 17 \\
No. cases involved in ASD gene screening & 1 & \\
\hline
\end{tabular}

Table 2 Comparison of age and sex characteristics between the healthy group and autism spectrum disorder (ASD) group

\begin{tabular}{|c|c|c|c|c|}
\hline Subgroup & Cases & Age (years) & \multicolumn{2}{|c|}{ Sex [cases (\%)] } \\
\hline Healthy group & 201 & $5.044 \pm 1.481$ & 119 (59.2) & $82(40.8)$ \\
\hline ASD group & 177 & $5.350 \pm 2.539$ & $151(85.3)$ & $26(14.7)$ \\
\hline Test statistic value & & $1.407^{\star}$ & \multicolumn{2}{|c|}{$28.027^{\#}$} \\
\hline
\end{tabular}

${ }^{*}$ t-value, ${ }^{*} \chi^{2}$-value.

was 5.8:1 (Table 1).

In the ASD group, the average age at diagnosis was $34.588 \pm 14.757$ months; the minimum month of diagnosis was 12 months and the maximum age was 10.5 years.

The age of children in both groups was expressed by mean \pm standard deviation. The average age for the 2 groups was $5.044 \pm 1.481$ years in the healthy group and $5.350 \pm 2.539$ in the ASD group. There was no significant difference in terms of age between groups $(t=1.407, \mathrm{P}=0.161)$. This suggest that there was a significant difference in sex between the healthy group and ASD group $(\mathrm{P}<0.01)$ (Table 2).

As shown in Table 2, there were sex-related differences between the ASD and healthy groups, which suggested that different risk factors are likely to lead to ASD in children of different sexes. Therefore, the risk factors of ASD in male and female children were analyzed.

\section{One-way analysis of variance (ANOVA) of factors among male ASD children}

As shown in Table 3, there were significant differences between the ASD group and healthy group for males in 14variables:maternal exposure to cigarette smoke, alcohol consumption of both parents living environment during pregnancy, hypertension in pregnancy, perinatal hypoxia, birth length, delivery method, amniotic fluid pollution, principal caregivers, time for breastfeeding feeding difficulties, relationship between parents and children, gastrointestinal disease, and respiratory infection $(\mathrm{P}<0.05)$.

\section{One-way ANOVA of factors among female ASD children}

As shown in Table 4, there were significant differences 
Table 3 Prenatal, postpartum, and perinatal factors in males

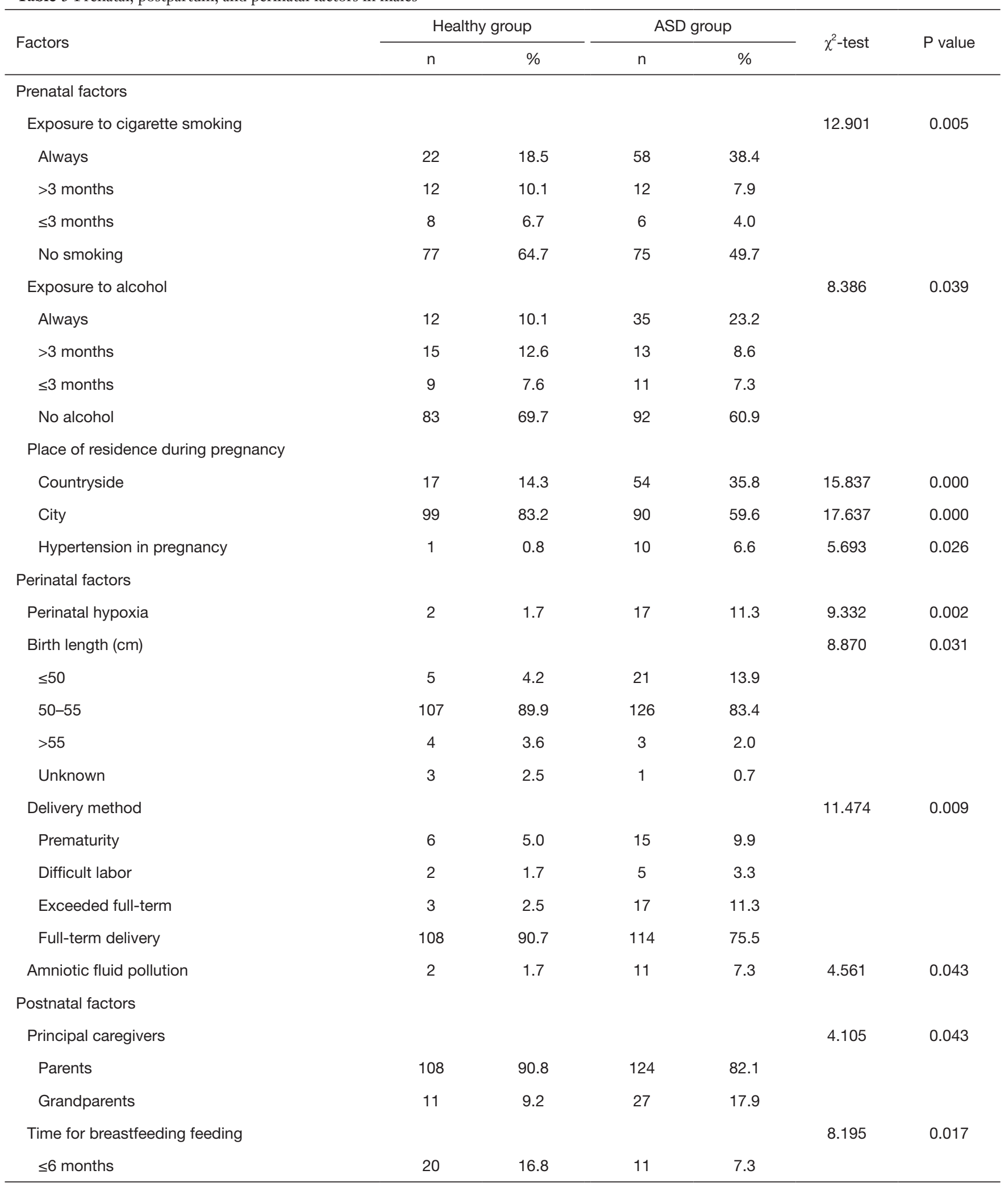

Table 3 (continued) 
Table 3 (continued)

\begin{tabular}{|c|c|c|c|c|c|c|}
\hline Factors & \multicolumn{2}{|c|}{ Healthy group } & \multicolumn{2}{|c|}{ ASD group } & $\chi^{2}$-test & $P$ value \\
\hline $6-12$ months & 25 & 21.0 & 25 & 16.6 & & \\
\hline$\geq 12$ months & 41 & 34.5 & 70 & 46.4 & & \\
\hline Feeding difficulties & 13 & 10.9 & 79 & 52.3 & 50.763 & 0.000 \\
\hline Gastrointestinal diseases & 39 & 32.8 & 13 & 8.6 & 24.990 & 0.000 \\
\hline Respiratory infection & 63 & 52.9 & 44 & 29.1 & 15.760 & 0.000 \\
\hline
\end{tabular}

ASD, autism spectrum disorder.

Table 4 Prenatal, postpartum, and perinatal factors in females

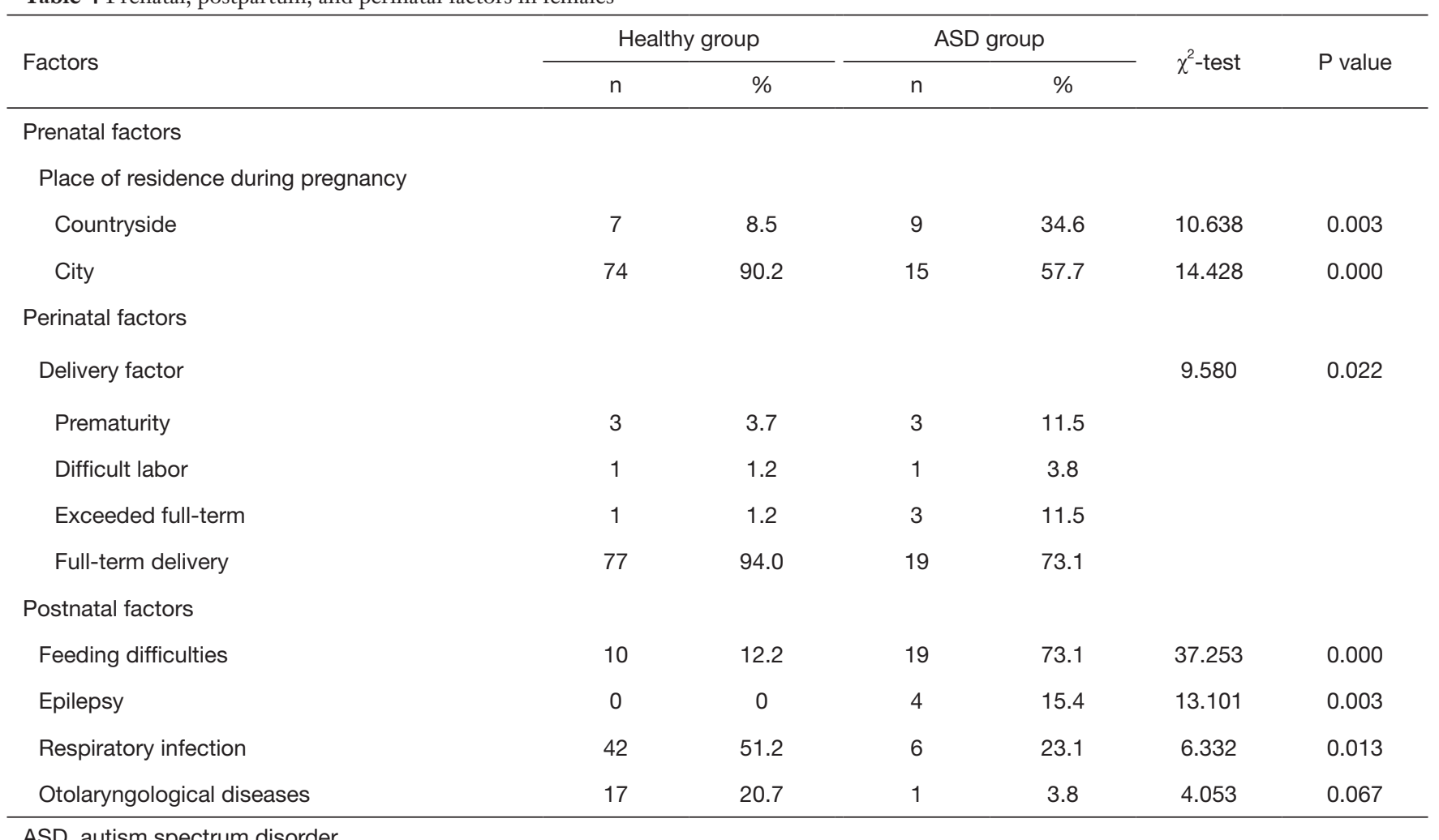

between the ASD group and healthy group for females in 6 variables as follows: place of residence during pregnancy, delivery method, feeding difficulties, epilepsy, respiratory infection, and otolaryngologic diseases $(\mathrm{P}<0.05)$.
Multivariate Logistic regression analysis of male autistic children

Taking children's autism as dependent variable, 14 items with statistical significance in one-way ANOVA of male 
Table 5 Analysis of risk factors of male autism

\begin{tabular}{lcccc}
\hline Variable & $\beta$ & $\mathrm{P}$ & $\mathrm{OR}$ & $95 \% \mathrm{Cl}$ \\
\hline Exposure to cigarette smoking & 1.823 & 0.006 & 6.191 & $1.678-22.838$ \\
Living in the countryside during pregnancy & 2.848 & 0.011 & 17.251 & $1.899-156.745$ \\
Perinatal hypoxia & 3.660 & 0.005 & 38.859 & $2.944-512.930$ \\
Feeding difficulties & 2.508 & 0.001 & 12.284 & $2.768-54.507$ \\
\hline
\end{tabular}

Table 6 Analysis of risk factors of male autism

\begin{tabular}{lcccc}
\hline Variable & $\beta$ & $\mathrm{P}$ & $\mathrm{OR}$ & $95 \% \mathrm{Cl}$ \\
\hline Feeding difficulties & 3.315 & 0.001 & 27.522 & $3.662-206.857$ \\
Living in the countryside during pregnancy & 3.196 & 0.009 & 24.438 & $2.243-266.281$ \\
\hline
\end{tabular}

group were put into logistic regression equation, and all variable regression method was used The results showed that feeding difficulties (OR: 12.284, 95\% CI: $2.768-$ 54.507), living in the countryside during pregnancy (OR: 17.251, 95\% CI: $1.899-156.745)$, exposure to cigarette smoking (OR: 6.191, 95\% CI: 1.678-22.838), and perinatal hypoxia (OR: 38.859 , 95\% CI: 2.944-512.930) were risk factors for ASD for male children (Table 5).

\section{Multivariate logistic regression analysis of female ASD children}

Similar to the analysis of the risk factors of male autistic children, 6 factors of statistical significance of the variance analysis of the single factor of the female group were put into the logistic regression equation, and the total variable regression method was adopted. The results showed that feeding difficulties (OR: 27.522, 95\% CI: 3.622-206.857) and living in the countryside during pregnancy (OR: 24.438, 95\% CI: 2.243-266.281) were risk factors for ASD for female children (Table 6).

\section{Discussion}

In the present study, we investigated 155 possible factors associated with the occurrence of ASD in children from Xuzhou, China using questionnaires. We found that the number of boys with ASD was significantly higher than that of girls, and the difference was significant, indicating that sex has possible high-risk factors in the pathogenesis of ASD. In the single-factor analysis of the incidence of ASD in boys, 11 factors were related to the occurrence of
ASD. Of these, 4 factors (feeding difficulties, living in the countryside during pregnancy, exposure to cigarette smoking and perinatal hypoxia) were determined by multiple factor regression analysis to be high-risk factors for ASD among girls.

In the single-factor analysis of the incidence of ASD in girls, 6 factors were related to the occurrence of ASD as follows: place of residence during pregnancy, delivery factor, feeding difficulties, epilepsy, respiratory infection, and otolaryngologic diseases. Multiple-factor regression analysis showed that 2 factors (feeding difficulties and living in the countryside) during pregnancy were risk factors for ASD among girls in the 6 related factors.

Therefore, from the results of this survey, at least some factors, such as feeding difficulties, living in the countryside during pregnancy, exposure to cigarette smoking and perinatal hypoxia, were ASD high-risk factors for children.

Many researchers have found that there is a sex difference in ASD children, with the sex ratio in prevalence estimates for boys versus girls generally being around $4: 1$ in $(2,3,16)$. It is generally believed that boys are significantly more likely to develop ASD than girls. Wing's work found a 15:1 ratio for the male-to-female incidence in Asperger's syndrome or higher functioning autism disorder and a 2:1 ratio in people with autism disorder and learning difficulties (16). In the present study, 177 children with ASD from Mainland China were analyzed, with a sex ratio of 5.8:1, which is slightly higher than the proportion of 4-5:1 reported in Western countries (17), and slightly lower than ASD in Chinese males and females, with a ratio of 6.5-9:1 (13).

The reason for the sex discrepancy is unclear. Fombonne found that male children had more severe socio- 
communicative symptoms than females (18). Wing first introduced the hypothesis of male gene innate vulnerability to support men's characteristics of autism, while females showed only partial autism (16). Schendel et al. also found that the birth defect rate of male ASD patients was higher than that of female ASD patients through a survey of 617 ASD children (19). Studies of twins showed that the heritability of ASD ranged between $77 \%$ and $99 \%$ (20). It has been suggested that females require more mutations at the genetic level to develop ASD. From a clinical point of view, the diagnostic rate of ASD in women may be lower, because women are better at overcoming their own difficulties to cover up their ASD symptoms, which may affect the diagnostic rate (21). Van WijngaardenCremers et al. showed that there were no significant sex differences in high-functioning ASD adults and pointed out that males and females might present with different ASD phenotypes (22), and this might affect diagnostic rates, as ASD in females is less well understood, and therefore, less easily detected.

Increasingly more researchers consider the difference in the prevalence of ASD between men and women to be of significance $(21,23,24)$. Further in-depths studies of sex-related pathogenicity load and susceptibility to ASD, and the stratification between males and females, that explore the pathogenesis and status of genetic, endocrine, epigenetic, and environmental levels associated with sex factors in the pathogenesis of ASD, will strengthen understanding of this condition.

Maternal smoking has been found to be associated with the development of ADHD or inattention, behavioral disorders and antisocial behavior, and emotional problems among children (25). Smoke is a complex mixture of gases and particulate matter, whether directly smoked or inhaled as secondhand smoke. The main components of smoke include nicotine, volatile organic compounds, and metals, such as cadmium, chromium, arsenic, lead, and many gas pollutants. Studies have found that once nicotine enters the bloodstream, it is distributed to all major organs of the body, such as the lungs, brain, and liver, and can freely enter the fetal body through the maternal placental barrier for circulation (26). Further studies have found that nicotine can interact directly with acetylcholine receptors in the fetal brain and affect the release of other neurotransmitters, including dopamine, noradrenaline, adrenaline, acetylcholine, serotonin (5-hydroxytryptamine), $\gamma$-aminobutyric acid (GABA), glutamate, and $\beta$-endorphin. In addition to nicotine, cigarette smoke contains heavy metals, such as lead and arsenic, that can damage the developing nervous system, influence the brain development, affect intellectual development, and cause behavioral damage after birth. Therefore, lead, mercury, arsenic, and cadmium are considered contributing factors to childhood autism $(27,28)$. Therefore, the exposure of pregnant women to cigarette smoke can increase the risk of ASD in their children.

In the present study, we found that living in rural areas during pregnancy was a risk factor for ASD. Raina et al. found that the incidence of autism in rural areas is higher than that in urban areas (29). Pesticide exposure is common in rural China. According to traditional Chinese customs, pregnant women engage in field work and they are exposed to pesticides during pregnancy. Increasing literature suggests that exposure to pesticides during pregnancy and early childhood is an environmental risk factor for ASDs (30). Through blood sampling during pregnancy, it was found that maternal exposure to high levels of organochlorine compound pesticides during pregnancy could affect the occurrence of ASD (31). Studies have found that organochlorine pesticides are persistent pollutants (32), which can act on the central nervous system through GABA receptor-mediated chloride channels (33). Similarly, it has been observed that maternal exposure to chlorpyrifos, an organophosphorus insecticide, increases the risk of autism in children (34). Animal experiments have also shown that pregnant rats exposed to low doses of glyphosate herbicides can create animal models similar to ASD (35). In addition to organochlorine pesticides, organophosphate insecticides can also affect the maturation and synaptic and axonal transmission of nerve cells by inhibiting the production of acetylcholinesterase in the brain, limiting the transmission of nerve signals in the peripheral and central nervous systems. Therefore, pesticide contamination can affect the development of the central nervous system through the placenta and blood-brain barrier, which is considered to be associated with ASD (36). There are also high levels of air pollutants in rural areas close to factories and waste incineration facilities. Studies have found that late pregnancy exposure to PM2.5 and PM10 is a risk factor for ASD in offspring (37). Therefore, more attention should be paid to the living environment during pregnancy. Particular environmental factors, such as pesticides, noise, and dust, may increase the risk of ASD (37). Perinatal ischemichypoxic (ICH) is defined as the occurrence of any one or more of the following acute (placental abruption, fetal malpresentation, dystocia, cord complications, 5-min Apgar 
score $<7$, respiratory distress syndrome, and asphyxia) and chronic (preeclampsia) conditions. Perinatal hypoxia has always been the focus of ASD etiology research. In a previous published study, more than 60 perinatal and neonatal factors were analyzed, and it found that a low 5-min Apgar score was a positive factor for ASD risk (9). Children with lower 5-min Apgar scores had a 3-fold increased risk of ASD.

Our results showed that the proportion of perinatal hypoxia in ASD patients was higher than that in the control group, especially in boys. Logistic regression analysis showed that the OR value was as high as 38.85 , that is, the possibility of ASD in children was 38.85 times higher than that in pregnant women without a history of perinatal hypoxia. Further studies have suggested that perinatal hypoxia is a risk factor for ASD (11). Duan et al. found that perinatal hypoxia may lead to excessive activation of the dopamine system after brain nerve damage, thereby increasing the risk of ASD (13). Increased maternal age is also considered a risk factor for autism. Studies have found that older mothers have a poor uterine environment and are prone to more obstetric complications, such as premature infants, low infant body weight, and brain hypoxia, which are associated with ASD (38). The present study also suggests that perinatal hypoxia is a risk factor for autism. Therefore, strengthening perinatal health care and reducing brain injury during birth are effective measures to prevent ASD in children.

The dietary behavior of children with ASD is one of the hotspots of current research (39). The main dietary behaviors of ASD children are eating difficulties, such as pickiness, refusal to eat, and destructive eating behavior. It is accompanied by rigid and repetitive dietary patterns that eventually lead to nutritional imbalances (17). Feeding difficulties associated with ASD formation include postnatal preference and anorexia (40). The present study also found that boys with feeding difficulties were 12 times more likely to develop ASD than boys with a normal diet. This may be associated with the difficulty of concentrating, narrow interests, and the abnormal perception of children with ASD, which can exhibit dietary problems, including partial eating, poor appetite, and digestive disorders. Feeding difficulties are considered a potential risk factor for ASD and a potential cause of symptoms. Compared with normal children, children with ASD have persistent gastrointestinal problems (41), including a higher rate of constipation (42). Another study showed that intestinal microorganisms can participate in the pathogenesis of ASD through the intestinal-brain axis (43). The evidence suggests a link between intestinal dysfunction and ASD symptoms.

Increasing evidence suggests a link between intestinal dysfunction and ASD symptoms. The most common micronutrient deficiencies in ASD are vitamin D, calcium, potassium, pantothenic acid, and choline. Timely supplementation of calcium and vitamin D is important for the skeletal health of ASD children. In addition, feeding difficulties may cause or aggravate the deficiency of important nutrients in the body, which in turn increases the likelihood of ASD. Previous clinical studies have shown that after a 3-month vitamin D supplement for ASD children, language function, stereotypic behavior, and social decline improved (44).

Considering the dietary behavior and dietary structure of ASD, dietary therapy is of particular importance (45). Some scholars believe that adjusting the diet can be used to improve children's ASD behaviors. A gluten-free casein diet is believed to improve children's behavioral symptoms, gastrointestinal symptoms, sleep quality, and aggressive behavior. However, the treatment is still at an early stage of research, so it is not certain whether a glutenfree and casein-free diet is really beneficial for children with ASD (46). There have been other recent reports that the ketogenic diet is considered to significantly improve the behavioral symptoms of ASD; however, this warrants further study (47).

\section{Conclusions}

Improving living environment during pregnancy, reducing pregnancy complications, avoiding maternal exposure to smoke pollution during pregnancy, and correcting and improving children's diet and diet quality, can be effective entry points for ASD prevention and treatment. Due to the limited sample size and representativeness of this study, the conclusions may not fully represent all the risk factors of ASD. Future studies should further expand the sample size and update the content of the survey.

\section{Acknowledgments}

Funding: None.

\section{Footnote}

Reporting Checklist: The authors have completed the STROBE reporting checklist. Available at http://dx.doi. 
org/10.21037/tp-21-54

Data Sharing Statement: Available at http://dx.doi. org/10.21037/tp-21-54

Conflicts of Interest: All authors have completed the ICMJE uniform disclosure form (available at http://dx.doi. org/10.21037/tp-21-54). The authors have no conflicts of interest to declare.

Ethical Statement: The authors are accountable for all aspects of the work in ensuring that questions related to the accuracy or integrity of any part of the work are appropriately investigated and resolved. This study was approved by ethics committee of the Affiliated Hospital of Xuzhou Medical University (NO.XYFY2020-KL151-01). Written informed consent was obtained from parents of guardians of study participants $<16$ years of age. All procedures performed in this study involving human participants were in accordance with the Declaration of Helsinki (as revised in 2013).

Open Access Statement: This is an Open Access article distributed in accordance with the Creative Commons Attribution-NonCommercial-NoDerivs 4.0 International License (CC BY-NC-ND 4.0), which permits the noncommercial replication and distribution of the article with the strict proviso that no changes or edits are made and the original work is properly cited (including links to both the formal publication through the relevant DOI and the license). See: https://creativecommons.org/licenses/by-nc-nd/4.0/.

\section{References}

1. Baio J, Wiggins L, Christensen DL, et al. Prevalence of Autism Spectrum Disorder Among Children Aged 8 Years - Autism and Developmental Disabilities Monitoring Network, 11 Sites, United States, 2014. MMWR Surveill Summ 2018;67:1-23.

2. Baird G, Simonoff E, Pickles A, et al. Prevalence of disorders of the autism spectrum in a population cohort of children in South Thames: the Special Needs and Autism Project (SNAP). Lancet 2006;368:210-5.

3. Lin JD. Medical care burden of children with autism spectrum disorders. Rev J Autism Dev Disord 2014;1:242-7.

4. Chaste P, Leboyer M. Autism risk factors: genes, environment, and gene-environment interactions.
Dialogues Clin Neurosci 2012;14:281-92.

5. Rybakowski F, Chojnicka I, Dziechciarz P, et al. The role of genetic factors and pre-and perinatal influences in the etiology of autism spectrum disorders-indications for genetic referral. Psychiatr Pol 2016;50:543-54.

6. Hallmayer J, Cleveland S, Torres A, et al. Genetic heritability and shared environmental factors among twin pairs with autism. Arch Gen Psychiatry 2011;68:1095-102.

7. Christensen DL, Braun KVN, Baio J, et al. Prevalence and Characteristics of Autism Spectrum Disorder Among Children Aged 8 Years - Autism and Developmental Disabilities Monitoring Network, 11 Sites, United States, 2012. MMWR Surveill Summ 2018;65:1-23.

8. Kim YS, Leventhal B L. Genetic epidemiology and insights into interactive genetic and environmental effects in autism spectrum disorders. Biol Psychiatry 2015;77:66-74.

9. Gardener H, Spiegelman D, Buka SL. Perinatal and neonatal risk factors for autism: a comprehensive metaanalysis. Pediatrics 2011;128:344-55.

10. Pasamanick B, Rogers ME, Lilienfeld AM. Pregnancy experience and the development of behavior disorder in children. Am J Psychiat 1956;112:613-8.

11. Hadjkacem I, Ayadi H, Turki M, et al. Prenatal, perinatal and postnatal factors associated with autism spectrum disorder. J Pediatr (Rio J) 2016;92:595-601.

12. Glasson E J, Bower C, Petterson B, et al. Perinatal factors and the development of autism: a population study. Arch Gen Psychiat 2004;61:618-27.

13. Duan G, Yao M, Ma Y, et al. Perinatal and background risk factors for childhood autism in central China. Psychiatry Res 2014;220:410-7.

14. Gao L, Xi QQ, Wu J, et al. Association between Prenatal Environmental Factors and Child Autism: A Case Control Study in Tianjin, China. Biomed Environ Sci 2015;28:642-50.

15. Volkmar FR, Cicchetti DV, Dykens E, et al. An evaluation of the autism behavior checklist. J Autism Dev Disord 1988;18:81-97.

16. Wing L. Sex ratios in early childhood autism and related conditions. Psychiatry Res 1981;5:129-37.

17. Elsabbagh M, Divan G, Koh YJ, et al. Global prevalence of autism and other pervasive developmental disorders. Autism Res 2012;5:160-79.

18. Fombonne E. Epidemiology of pervasive developmental disorders. Pediatr Res 2009;65:591-8.

19. Schendel DE, Autry A, Wines R, et al. The co-occurrence of autism and birth defects: prevalence and risk in 
a population-based cohort. Dev Med Child Neurol 2009;51:779-86.

20. Colvert E, Tick B, McEwen F, et al. Heritability of autism spectrum disorder in a UK population-based twin sample. JAMA Psychiatry 2015;72:415-23.

21. Lai MC, Lombardo MV, Pasco G, et al. A behavioral comparison of male and female adults with high functioning autism spectrum conditions. PloS One 2011;6:e20835.

22. Van Wijngaarden-Cremers PJM, van Eeten E, Groen $W B$, et al. Gender and age differences in the core triad of impairments in autism spectrum disorders: a systematic review and meta-analysis. J Autism Dev disord 2014;44:627-35.

23. Wilson CE, Murphy CM, McAlonan G, et al. Does sex influence the diagnostic evaluation of autism spectrum disorder in adults? Autism 2016;20:808-19.

24. Howe YJ, O'Rourke JA, Yatchmink Y, et al. Female autism phenotypes investigated at different levels of language and developmental abilities. J Autism Dev Disord 2015;45:3537-49.

25. Tiesler CM, Heinrich J. Prenatal nicotine exposure and child behavioural problems. Eur Child Adolesc Psychiatry 2014;23:913-29.

26. Dempsey D A, Benowitz NL. Risks and benefits of nicotine to aid smoking cessation in pregnancy. Drug Saf 2001;24:277-322.

27. Dickerson AS, Rahbar MH, Bakian AV, et al. Autism spectrum disorder prevalence and associations with air concentrations of lead, mercury, and arsenic. Environ Monit Assess 2016;188:407.

28. Pamphlett R, Jew SK. Locus ceruleus neurons in people with autism contain no histochemically-detectable mercury. Biometals 2016;29:171-5.

29. Raina SK, Chander V, Bhardwaj A K, et al. Prevalence of autism spectrum disorder among rural, urban, and tribal children (1-10 years of age). J Neurosci Rural Pract 2017;8:368-74.

30. von Ehrenstein OS, Ling C, Cui X, et al. Prenatal and infant exposure to ambient pesticides and autism spectrum disorder in children: population based case-control study. BMJ 2019;364:1962.

31. Lyall K, Croen LA, Sjödin A, et al. Polychlorinated biphenyl and organochlorine pesticide concentrations in maternal mid-pregnancy serum samples: association with autism spectrum disorder and intellectual disability. Environ Health Perspect 2017;125:474-80.

32. Xu X, Dailey AB, Talbott EO, et al. Associations of serum concentrations of organochlorine pesticides with breast cancer and prostate cancer in U.S. adults. Environ Health Perspect 2010;118:60-6.

33. Ma DQ, Whitehead PL, Menold MM, et al. Identification of significant association and gene-gene interaction of GABA receptor subunit genes in autism. Am J Hum Genet 2005;77:377-88.

34. Landrigan PJ. What causes autism? Exploring the environmental contribution. Curr Opin Pediatr 2010;22:219-25.

35. Herzine A, Laugeray A, Feat J, et al. Perinatal exposure to glufosinate ammonium herbicide impairs neurogenesis and neuroblast migration through cytoskeleton destabilization. Front Cell Neurosci 2016;10:191-203.

36. Bradman A, Barr DB, Claus Henn BG, et al. Measurement of pesticides and other toxicants in amniotic fluid as a potential biomarker of prenatal exposure: a validation study. Environ Health Perspect 2003;111:1779-82.

37. Kalkbrenner AE, Windham GC, Serre ML, et al. Particulate matter exposure, prenatal and postnatal windows of susceptibility, and autism spectrum disorders. Epidemiology 2015;26:30-42.

38. Parner ET, Baron-Cohen S, Lauritsen MB, et al. Parental age and autism spectrum disorders. Ann Epidemiol 2012;22:143-50.

39. Kral TVE, Eriksen WT, Souders MC, et al. Eating behaviors, diet quality, and gastrointestinal symptoms in children with autism spectrum disorders: a brief review. J Pediatr Nurs 2013;28:548-56.

40. Guisso DR, Saadeh FS, Saab D, et al. Association of autism with maternal infections, perinatal and other risk factors: a case-control study. J Autism Dev Disord 2018;48:2010-21.

41. Bresnahan M, Hornig M, Schultz AF, et al. Association of maternal report of infant and toddler gastrointestinal symptoms with autism: evidence from a prospective birth cohort. JAMA Psychiatry 2015;72:466-74.

42. Greenlee JL, Mosley AS, Shui AM, et al. Medical and behavioral correlates of depression history in children and adolescents with autism spectrum disorder. Pediatrics 2016;137:S105-14.

43. Vuong HE, Hsiao EY. Emerging roles for the gut microbiome in autism spectrum disorder. Biol Psychiatry 2017;81:411-23.

44. Saad K, Abdel-Rahman AA, Elserogy YM, et al. Vitamin $\mathrm{D}$ status in autism spectrum disorders and the efficacy of vitamin D supplementation in autistic children. Nutr Neurosci 2016;19:346-51.

45. Graf-Myles J, Farmer C, Thurm A, et al. Dietary 
adequacy of children with autism compared to controls and the impact of restricted diet. J Dev Behav Pediatr 2013;34:449-59.

46. Diolordi L, del Balzo V, Bernabei P, et al. Eating habits and dietary patterns in children with autism. Eat Weight
Disord 2014;19:295-301.

47. Evangeliou A, Vlachonikolis I, Mihailidou H, et al. Application of a ketogenic diet in children with autistic behavior: pilot study. J Child Neurol 2003;18:113-8.

Cite this article as: Yong Z, Dou Y, Gao Y, Xu X, Xiao Y, Zhu H, Li S, Yuan B. Prenatal, perinatal, and postnatal factors associated with autism spectrum disorder cases in Xuzhou, China. Transl Pediatr 2021;10(3):635-646. doi: 10.21037/tp-21-54 